\title{
THE BOILER FURNACE NUMERICAL MODELING OF BURNING NON-STANDARD FUEL
}

\author{
A. V. Gil ${ }^{1, *}, O$. M. Koksharev ${ }^{1}, D$. V. Lebed ${ }^{2}$, and $A$. V. Starchenko ${ }^{3}$ \\ ${ }^{1}$ National Research Tomsk Polytechnic University, 634050 Tomsk, Russia \\ ${ }^{2}$ OJSC DGK, Vladivostok, Russia \\ ${ }^{3}$ National Research Tomsk State University, 634050 Tomsk, Russia
}

\begin{abstract}
The aim of paper is to study the combustion processes of organizing non-standard fuel burning using a numerical approach in a boiler unit BKZ-210-140 with steam capacity of $210 \mathrm{t} / \mathrm{h}$. The EulerLagrange aerothermochemical technique of describing physical and chemical processes in the furnace volume by the FIRE 3D application package on the base was used. Special attention is paid to the numerical modeling results conclusion of the aerodynamics processes, heat exchange, and combustion in the furnace volume.
\end{abstract}

\section{Introduction}

Often in the course of thermal power plants continuous operation standard solid fuel exceeded its storage. In such event boiler operation at the off-design coal is prohibited and therefore it is necessary to test the boiler for possibility of non-standard fuel burning [1].

This paper considers the possibility of organizing non-standard fuel burning using a numerical approach $[2,3]$ in a boiler unit with steam capacity of $210 \mathrm{t} / \mathrm{h}$, which are common in regions of Siberia, the Far East and Primorski Krai.

\section{Problem statement}

The research object is the vertical water-tube boiler unit E-210-140 with single drum, natural circulation, double-pass configuration and dry-ash removal. Combustion chamber is equipped with four straight-flow burners with tangential layout, has volume of $1093 \mathrm{~m}^{3}$ and a cross-sectional size of $7424 \times 7808 \mathrm{~mm}$. The standard fuel is Chihezsky brown coal.

As an alternate fuel adopted Pavlovsky brown coal. Table 1 shows the basic burning characteristics of the design and alternate coal [4].

\footnotetext{
${ }^{*}$ Corresponding author: andgil@,tpu.ru
} 
Table 1. Burning characteristics of the design and alternate coal.

\begin{tabular}{|l|c|c|c|}
\hline & Unit of measure & Chihezsky brown coal & Pavlovsky brown coal \\
\hline Brand & - & $1 \mathrm{~B}$ & $1 \mathrm{~B}$ \\
\hline Humidity & $\%$ & 43.0 & 41.5 \\
\hline Ash & $\%$ & 12.5 & 19.6 \\
\hline The sulfur content & $\%$ & 0.2 & 0.4 \\
\hline The carbon content & $\%$ & 30.3 & 25.7 \\
\hline The hydrogen content & $\%$ & 2.5 & 2.3 \\
\hline The nitrogen content & $\%$ & 0.4 & 0.3 \\
\hline The oxygen content & $\%$ & 11.2 & 10.2 \\
\hline Lower heating value of the fuel & $\mathrm{MJ} / \mathrm{kg}(\mathrm{kkal} / \mathrm{kg})$ & $10.72(2560)$ & $9.13(2180)$ \\
\hline
\end{tabular}

Comparing the two types of coal, it can be noted that mineral content of the Pavlovsky brown coal is higher and carbon content is lower. Therefore, the non-standard fuel value is lower that increase its consumer in comparison to the standard fuel.

\section{Mathematical model}

In this study, the Euler-Lagrange aerothermochemical technique of describing processes by the FIRE 3D application package on the base was used $[5,6]$. Turbulent gas properties are calculated using the " $k-\varepsilon$ " two-parameter turbulence model. Radiative heat transfer is represented within the P1 method approximation of spherical harmonics.

Tasks are solved numerically on non-staggered grids in the Cartesian coordinate system using the relaxation method. Discretization of initial differential equations is performed by using the finite volume method [7]. Diffusion flow on the facets of the control volume are approximated by a central difference scheme, which has the second order of accuracy. To determine the convective flows Van Leer monotonic upwind scheme of the second-order was used.

\section{Results and discussion}

Figure 1 shows the formation of dead area close to the aerodynamic nose, topping, back and front walls. The velocity in these areas does not exceed $1.5 \mathrm{~m} / \mathrm{s}$. With the rising of gas circuit, velocity is aligned across the width and depth of the furnace and reach the average value of $10 \mathrm{~m} / \mathrm{s}$. In the horizontal cross section along the axis of the burners, maximum speeds occur at the outlet of embrasures - more than $16 \mathrm{~m} / \mathrm{s}$. With the approaching the axis of combustion chamber the velocity is reduced and has a value of about $10 \mathrm{~m} / \mathrm{s}$. When flows encounter occurs, there are the formation of vortex in vertical planes in above and below regions next to the zone of burners.

Figure 2 shows the pattern of temperature distribution in different sections. Analyzing these results, three zones can be highlighted. The first one is the dry-bottom hopper zone: the temperature in this area is about $1300 \mathrm{~K}$. The second one is the zone from the drybottom hopper beginning to the aerodynamic nose: the temperature here is about $700 \mathrm{~K}$. The third one begins from aerodynamic nose and continues above it: the temperature range around $1400 \mathrm{~K}$.

Temperature distribution fields in furnace volume is chaotic. There are local zones of high temperatures - the top right corner of furnace. 


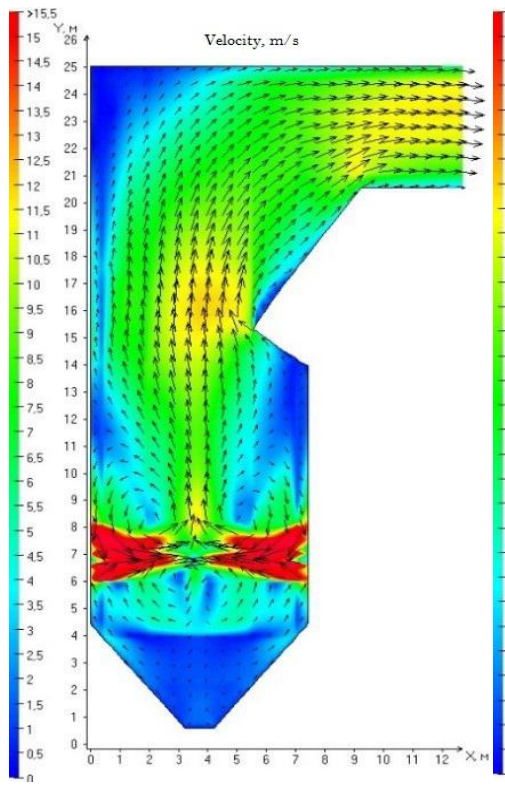

a)

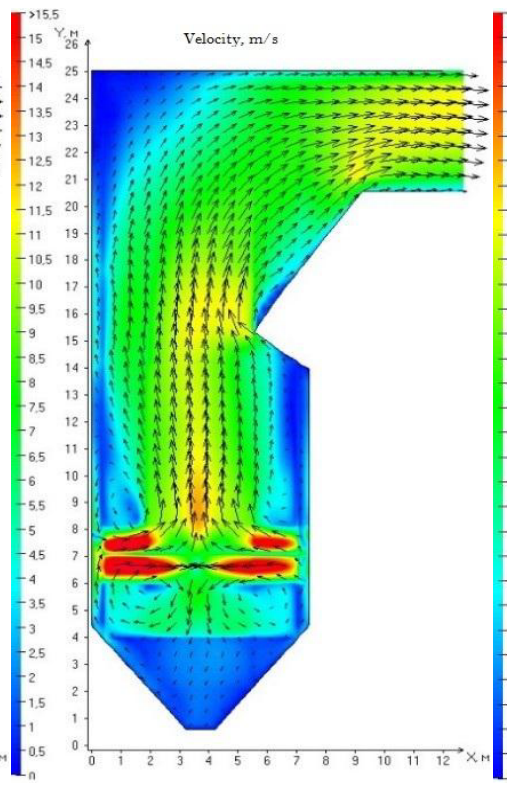

b)

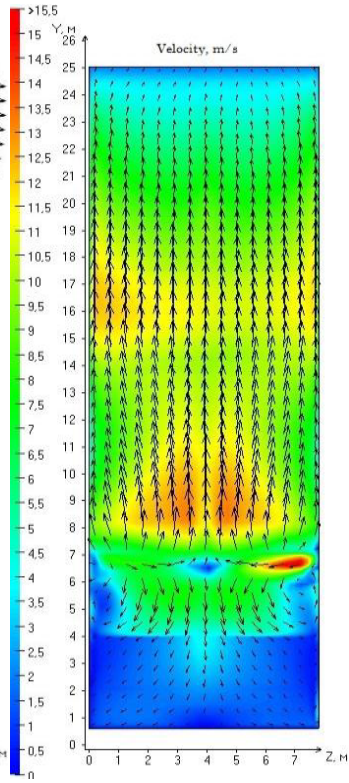

c)

Fig. 1. The aerodynamic flow pattern in a longitudinal cross-section: a - at a distance of 1 meter from the side wall; $\mathrm{b}$ - along the transverse axis of the furnace; $\mathrm{c}$ - along the longitudinal axis of the furnace.

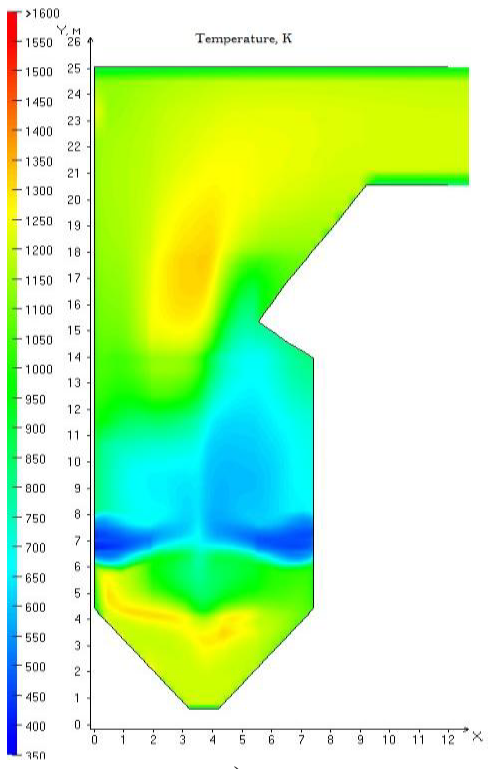

a)

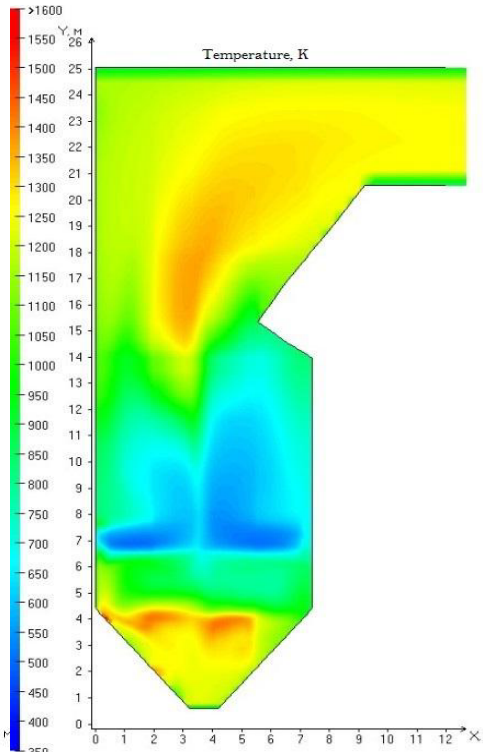

b)

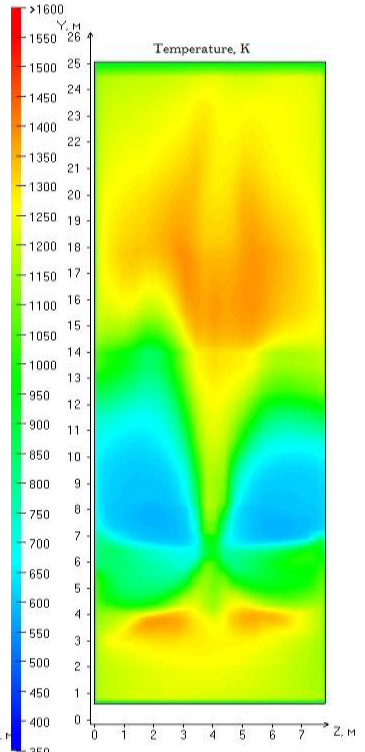

c)

Fig. 2. The temperature distribution in the longitudinal cross-section: a - at a distance of 1 meter from the side wall; $\mathrm{b}$ - along the transverse axis of the furnace; $\mathrm{c}$ - along the longitudinal axis of the furnace.

Figure 3 shows a graph of the average and maximum temperatures in the horizontal cross-section of the furnace. 


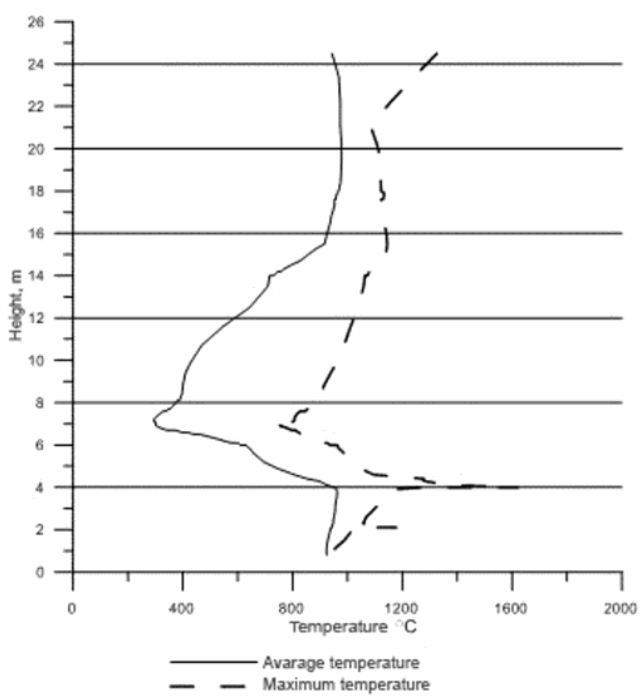

Fig. 3. Height variation of the maximum mean integral temperature values in the horizontal crosssection of the furnace.

From this graph it is seen that the temperature in the bottom of the furnace is from 950 to $1000{ }^{\circ} \mathrm{C}$; then it gradually decreases - at the level of the burners the temperature is about $300{ }^{\circ} \mathrm{C}$; then increases again - at the furnace exit it is $1000{ }^{\circ} \mathrm{C}$.

\section{Conclusions}

The resulting furnace exit gas temperature is slightly different from the calculated by normative method [4] $\left(\sim 30^{\circ} \mathrm{C}\right)$, what indicates the adequacy of accepted models and approaches.

Overall, the results of mathematical modeling prove the possibility of Pavlovsky brown coal burning in researched boiler furnace. The picture of the particles distribution in the furnace volume uniquely corresponds to its aerodynamic structure and confirms the vortex nature of their movement. In addition, the temperature distribution in the longitudinal crosssection picture shows that screen surfaces work in less loaded mode and less prone to slagging while combusting of the Pavlovsky brown coal.

\section{References}

1. A.V. Zavorin, A.V. Gil, P.S. Khaustov, R.B. Tabakaev, D.A. Buslov, IOP Conf. Ser.: Mater. Sci. Eng. 66, 012038 (2014)

2. Z.F. Tian, P.J. Witt, M.P. Schwarz, W. Yang, Energy Fuels 26, 2 (2012)

3. S. Belosevic, M. Sijercic, S. Oka, D. Tucakovic Int. J. Heat Mass Transfer 49 (2006)

4. Thermal Computation of Boilers. Normative Method, 3rd Edition, (NPO TsKTI, St. Petersburg, 1998)

5. A.V. Gil, A.V. Starchenko, Thermophysics and Aeromechanics 19, 3 (2012)

6. A.V. Gil, A.Y. Gil, EPJ Web Conf. 82, 01044 (2015)

7. N.V. Vizgavljust, A.V. Starchenko, A.V. Gil, T.S. Taylasheva, EPJ Web Conf. 82, 01044 (2015) 